\title{
The Negative Impact of Smartphones and How Teachers Improve Teaching Activities through Smartphones
}

\author{
Nan Yin ${ }^{1, *}$ \\ ${ }^{1}$ Business School, Nanjing Xiaozhuang University, Hongjing District, Nanjing City, China \\ *Corresponding author
}

Keywords: Smartphone; Teaching; Two-Way Communication.

Abstract: As the functions of smart phones are becoming more and more diverse, they can not only chat on the Internet, but also play games. As a result, college students nowadays become bowers. They are using smart phones all the time, affecting classroom lectures and after-school learning. Therefore, this study explores the negative impact of smart phones, as well as the characteristics of smart phones in teaching activities. Finally, combined with these characteristics, it discusses how teachers use smart phones to improve classroom teaching activities.

\section{Research Status}

College students are the main group of mobile phone users. The convenience and diversity of mobile phones always have irresistible charm for them. The use of mobile phones takes up a lot of their time. It is believed that many teachers will experience such a test in class: students are very attentive and hard-working, close to see, they are playing Wechat or mobile games. Unlike previous Internet addiction, it often causes high truancy rate of students and has less impact on teachers. However, in recent years, mobile phone addiction is prevalent. Students sit quietly and obediently in the classroom. He is completely integrated into his mobile phone world without knowing the existence of teachers. Such a situation is testing teachers' accomplishment. How to deal with it? It is believed that many teachers are facing a difficult problem.

The function of smart phone is not just chatting or online games. It can guide students to use information technology correctly in thematic inquiry learning activities, face up to and make good use of the function of information technology, and then it can give full play to the learning convenience brought by science and technology. Learning places can not only be in schools or residential areas, but also extend to the whole world. Through the global Internet, teachers and students share with teachers and students in classrooms all over the world to create multi-cultural learning with added value.

Due to the advancement of computer technology, the reduction of hardware volume and the popularization of network, the function of mobile phone has been used to communicate with people, evolving and evolving continuously. Modern mobile phone is not only a mobile phone, but also a mobile computer, which cooperates with the Internet and various computer-related applications. People can search data, videos, shopping, play online games, watch movies or idols, GPS navigation, make Internet calls, watch real-time traffic conditions and monitor their homes anytime 
and anywhere. Smartphones can be said to be a comprehensive personal mobile minicomputer. What used to be done through desktop computers can be accomplished only by using smart phones. The integration of communication, play and network has changed our way of interpersonal interaction and communication, changed our mode of life, and brought human history into a new era.

There is no doubt that the functions of smart phones are becoming more and more diverse and powerful, which brings people a lot of convenience. Nowadays, whether it is online, social, entertainment, work, or mobile payment, people can use mobile phones with only one finger. However, it is also because it is like an invincible superman, providing many functions, so that many people's lives rely on it, tied together with it.

\section{Negative Effects of Smart Phones}

With the efforts of experts and scholars, the functions of smart phones are increasing, which brings many conveniences to human beings. Mobile phones can increase the frequency of teenagers' communication and expand the opportunities of interpersonal relationships. In addition, mobile phone network services (such as dating sites) or game functions have also become a way to eliminate loneliness. However, the use of smart phones also generates a series of negative effects, including physical, interpersonal communication, learning and expression, psychological and other aspects, and can not be ignored. In terms of physical impact, machine inseparability has become the current culture, especially in order to attract customers, mobile payment companies have provided a variety of convenient means of payment, so that people will pick up their mobile phones to slide back and forth screen, surf the Internet, check e-mail, watch Wechat, QQ, play online games and so on. Especially young people will never go offline on the Internet, mobile phones will never turn off, developing a new type of civilized disease. Because they look down at the screen for a long time, and when they operate mobile phones, their shoulders will be rigid in a position for a long time, which will easily lead to muscle strain. Therefore, many young people suffer from mobile phone syndrome and cervical spondylosis at an early age. In addition, long-term staring at the screen with smaller screen is prone to eye wear, such as eye acerbity, dry eyes and other symptoms, or myopia younger.

In terms of interpersonal communication, the recent popular micro-mail makes people pay close attention to the micro-message information all the time, receive the information and reply in real time. They hang their whole heart on the micro-message while doing nothing. At the same time, he also hopes that others can reply in real time. If they can't receive the information from others, they will be restless and constantly check the information. It causes psychological pressure and interpersonal tension on both sides of sending and receiving, and has a negative impact on interpersonal relationship.

In terms of learning and expression, if teenagers keep a close eye on the screen all day long and get used to the high-intensity and novel information on the screen, it may affect their concentration in learning. American studies have found that an additional hour of screen staring every day increases the likelihood of subsequent inattention problems by $9 \%$. In addition, because the smart phone screen size is small, whether typing or handwriting is not as convenient and fast as the general computer, so users use short or omitted terms, or use mapping to contact others, simple and innovative symbols and words instead of traditional sentences, which virtually reduces the writing ability of the language. Force makes the development of literature more and more shallow. Moreover, the complete function of mobile phones is meant to bring convenience and save time, but it also stealthily eats the user's free time and thinking ability. Anyway, with mobile phones, everything will be done, and the brain is now a spare object. 
In terms of psychological impact, because mobile Internet allows mobile phone users to access the Internet at any time and anywhere, coupled with the popularity of social networking sites, it is easy for users to spend all day on the Internet, chat with people through the network, or prefer to browse the Web aimlessly, ignoring the academic, work, leisure or sleep and other business, and the original. Friends are drifting away. Many mobile phone users are often kidnapped by mobile phones. Smart phones have been on the market for only a few years, but most modern people can no longer live without mobile phones. That is, the so-called phobia without mobile phones, people forget to take mobile phones out or mobile phones without electricity will feel anxious, mobile phones can not receive information or can not access the Internet will also feel anxious. Every destination will first look for wireless Internet service, even when sleeping, they will worry about others unable to contact themselves and put the mobile phone around, or worry about losing contact with others without the mobile phone.

\section{The Characteristics of Smart Phone in Teaching}

Smart phones are used more and more widely in action learning. Researchers synthesize the views of relevant scholars and summarize the following characteristics.

\subsection{Convenience of Learning Places}

Smart phones have the characteristics of small size, easy to carry and flexible operation. Students with smart phones can study anywhere, and the learning place is no longer restricted by the venue. Self-regulated learning can be carried out at any time and anywhere. Liu Yongguang (2016) said that the functions of smart phones are becoming more and more perfect and popular, and students' learning styles have changed greatly. The mobile learning of college students based on smart phones has become an important means of higher education teaching. College students with smart phones can access shared resources and exchange information at any time and anywhere. Merchant (2012) said that smartphones make mobile learning more flexible, free from time and space constraints, and that learning can be more interactive and customized according to personalization.

\subsection{Timeliness of Problem Solving}

In teaching, with the help of the multimedia function of smart phone, the teaching quality and learning efficiency can be improved, and the related problems of action learning can be effectively solved. He Hangfei (2017) said that the process of learning is the process of answering questions. Teachers need to guide or view professional data to determine the problem. When there are problems in learning. If we can solve the problem in time and effectively, we can effectively improve the fun and interest of learning, and mobile phone action learning through online communication and access to data can realize the problems encountered in self-learning.

\subsection{Diversity of Teaching and Learning Modes}

Huang (2016) studies show that integrated learning on smartphones offers both opportunities and challenges. Students and teachers can use smart phones to achieve multiple ways of learning and teaching, with different concepts of use. Research by Huang and Wu (2017) shows that smartphone-oriented flip teaching is more effective than traditional classroom narrative. And learners can use the smart phone app to learn by action, which can help learners to have a significant effect in learning experience. Hassanzadeh, Kanaani and Elahi (2012) indicate that mobile learning through smart phones can integrate various types of media, and can carry out course learning activities anytime, anywhere. Sun Gengxin and Han Rongqing (2016) said that with the popularization of mobile Internet technology, the application of smart phone APP has been widely used in the daily teaching of students at all levels of schools. The APP application of smart 
phone has the teaching advantages and characteristics that PC software and system do not have. Applying smart phone APP to higher education not only reflects the innovation of teaching methods, but also is an important way to improve classroom teaching efficiency, promote curriculum reform and reorganize teaching resources. Ye Miao (2016) research shows that the use of smart phones and app for practical teaching, interactive feedback with students, stimulate students' interest in learning, combined with the flip classroom teaching model to achieve pre-class preview, after-class review, assignment, knowledge questions and answers, the depth and breadth of the classroom have been extended and expanded.

\subsection{Repeatability of Learning Data}

In learning, there are many situations that require repeated watching and rehearsal, for example, in the learning of experimental operation, which has more details. Most of the time, teachers have limited number of exercises. The experiment process can be photographed by a smart phone, which can be watched repeatedly when it is necessary to identify and correct its erroneous actions. Therefore, with the help of technology products such as smartphones, we can watch movies repeatedly, deepen the learning effect, pause and turn back through teaching movies, and most of the classroom time can be used for individualized guidance of students.

\subsection{Interaction in the Learning Process}

Pimmer (2016) believes that most people use smartphones in general and can communicate and transmit information synchronously through technological products. The applications derived from these smartphones not only affect all levels of education, but also provide innovation in action learning and increase interactive participation in learning activities. He Hangfei (2017) said that with the continuous development of communication technology, smart phones can carry modern communication software, such as Wechat and other modern communication software. When confronted with problems that need to be exchanged, they can communicate online with teachers and classmates. Therefore, the interaction of autonomous learning can be easily realized. The way of communication between teachers and students can be further improved. The traditional classroom extends to the network. Research by Bose and Lowenthal (2016) shows that guides can help teach content, communicate and share information through mobile devices such as smart phones. Research by Baccarani and Tucker (2016) found that students can help teachers and students interact through the technological products of smartphones, and through the assistance of smartphones, they can complete learning online. When they return to the classroom, they can promote students' motivation to participate in classroom activities.

\subsection{Autonomy of Learning Activities}

Sperling (2015) used Apple Watch to study the learning strategies of students using technology to improve their autonomy through the pilot action learning program. Students can follow the learning process and adopt special learning strategies to study independently. Students receive learning information through wearable technology products, requiring students to learn how, what and where to learn. This learning process is more effective than other learning methods. Huang (2016) research shows that students can learn more spontaneously through smartphones and become more positive about the future of integrating smartphones into learning. Bose et al. (2016) said that mobile devices such as smart phones could facilitate the design of extra-curricular homework for students, enhance students' digital literacy, and evaluate strategies could also be replaced. Zeng Silin et al. (2016) said that the functions of smart phones are becoming more and more perfect and popular. Students learn on the basis of smart phones in order to obtain shared resources and exchange information, and can fully promote students' cooperation, initiative and enthusiasm in learning.

In conclusion, the researchers believe that the use of smart phones in action learning includes the 
convenience of learning places, the timeliness of problem solving, the diversity of teaching and learning modes, the repeatability of learning data, the interaction of learning process and the autonomy of learning activities. Therefore, the integration of smart phones and mobile learning provides both opportunities and challenges. In the future, students can use smart phones to achieve multiple learning opportunities, and their learning experience will also have a positive effect.

\section{How do Teachers Use Smartphones in Teaching Scenarios}

Teachers should not stick to the traditional knowledge imparting, flip the classroom, find the fundamental way to teach students in the information rich environment and how to do well in educational innovation. This is the key to solve the problem.

\subsection{Enliven the Classroom Atmosphere and Improve Learning Motivation}

If smart phones can be used flexibly in classroom teaching, classroom atmosphere can be activated and teaching effect can be improved. Liu Yongguang (2016) through the smart phone, allows students to conduct self-video, broadcast, self-assessment training anytime and anywhere, students to take action to self-assessment and mutual evaluation, group recording products, showing, evaluating, summarizing, reflecting on the progress of the learning process, the appropriate method of practice, etc., to students' learning. Learning motivation has had a positive impact. Min Xuekai (2014) through the active classroom atmosphere, enhance the spirit of cooperation, encourage and guide students to use smart phones reasonably in the process of physical education teaching, first of all, make students feel that the teaching method of physical education teachers is novel, the management method is scientific, reasonable and humanized, invisibly narrowing the distance between teachers and students; Secondly, for students, the use of smart phones in teaching time is an exciting point in itself, which is different from other teaching activities. It plays a role in the activity of classroom atmosphere. Thirdly, when teachers and students and students watch photos or films of experimental technology operation, they learn from each other. The process is also the process of emotional exchange and communication.

\subsection{Two-Way Communication, Sharing and Group Cooperative Learning}

Practical teaching is carried out by using smart phone and application APP, interactive feedback with students is provided to stimulate students' interest in learning. The interactive function of smart phones can reward students through symbols in teaching and communicate with parents in both directions. The photographic function of smart phones can take wonderful pictures of the teaching process, share with teachers and students, and strengthen the emotional communication between teachers and students. Lu Yongjun (2015) said that the hybrid teaching method combined with smart phone video in the practical operation class experimental research, through grouping and cooperation, students learn from each other, find the right way to truly help students learn and lasting memory. In addition, students have been videotaped many times, and their films will be evaluated, even collected or disseminated on the Internet. Invisible video pressure is also the driving force for positive development of learning.

\subsection{Unlimited Learning, Free and Autonomous Learning}

Smart phones are teachers in students' pockets at any time and anywhere. Students use fragmented time to watch movies and imitate bare-handed exercises, which deepens the understanding of action points, difficulties and details, and promotes students to master action faster. App of smart phone is introduced into teaching, which helps teachers to manage and guide students in class, and extends teaching to after-school time, so as to improve the quality of teaching and improve the comprehensive quality of College students. Action learning is a new way of learning, 
which can be learned anytime, anywhere and everywhere. With the popularization of 4G network and the arrival of 5G era, real-time communication tools such as QQ and Wechat in smart phones can extend the content of physical education teaching to students' life after class. The training mode of teaching skills through smart phones and Internet can promote students' cooperation, initiative and enthusiasm in learning, realize the training of teaching skills at any time, in life, in science, in entertainment, and in game, so as to improve students' teaching ability. According to the questionnaire survey, about $80 \%$ of the students said that micro-classes based on smart phones are very suitable for assisting self-directed practice, which helps to enhance students' sense of experience, stimulate their interest in learning practical skills and cultivate their learning awareness. Students continue to use smart phones for self-learning, self-testing and self-evaluation, which is conducive to the cultivation of good learning habits and the improvement of learning ability. Smart phone should be the most ideal learning tool and amateur instructor for contemporary college students in class.

\section{Acknowledgement}

Foundation Project: Nanjing Xiaozhuang University's School-level Educational Research and Reform Project in 2019 "Reflection and Reconstruction of Applied Talents Training Model for E-Commerce Major Based on CDIO-OBE".

\section{References}

[1] Hu Taotao. Research on the impact of smart phones on teaching [J]. Journal of Taiyuan Normal University (Social Science Edition), 2015 (2).

[2] Chen Xutang. The Impact of Smart Phone on Classroom Teaching --- Taking Theory Teaching as an Example [J]. Heilongjiang Education: Higher Education Research and Evaluation, 2015 (11): 17-19.

[3] Li Chao. Study on the Negative Effects of Smartphones on College Classroom Teaching [J]. Electronic Journal in the New Educational Age: Teachers' Edition, 2014 (8).

[4] Feng Wenting, Zhao Wei and Liu Longfei. Exploration of the application of smart phones in college classroom teaching [J]. Science and Education Literature Collection (Mid-term), 2015 (7): 34-35.

[5] Ruan Jia Quan. Application of smart phones and "Internet + Classroom" in the teaching of mechanic colleges and universities to explore [J]. computer knowledge and technology, 2016, 12 (19): 114-115. 